\title{
War Questions: Uma proposta gamificada para criação e resolução de questões contextualizada
}

\author{
Neide Aparecida Alves de Medeiros ${ }^{1}$, Edith Cristina da Nóbrega ${ }^{1}$, Elvis Medeiros \\ de Melo ${ }^{1}$, Nathalie Rose Ramos da Fonseca Araújo ${ }^{1}$, Rodolfo Morais da Costa ${ }^{1}$, \\ Charles Andrye Galvão Madeira ${ }^{1}$, José Guilherme da Silva Santa Rosa ${ }^{2}$
}

Instituto Metrópole Digital - Universidade Federal do Rio Grande do Norte (UFRN) Av. Sen. Salgado Filho, 3000 - Lagoa Nova, CEP: 59.078-970 - Natal - RN - Brasil

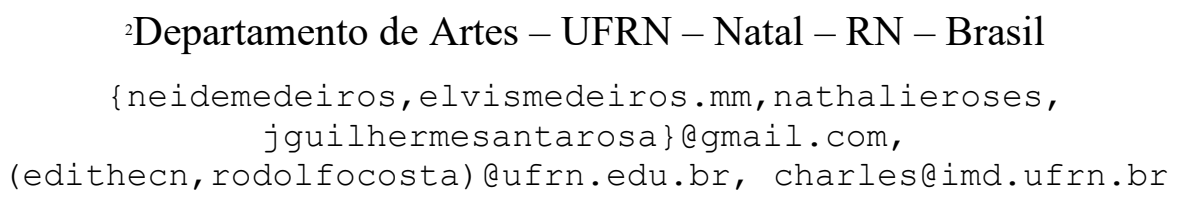

\begin{abstract}
Discussions around the potential of games have transformed teaching and learning and challenged educators to find applicable solutions that effectively contribute to student learning. Integrating gamification and the use of technological resources in educational environments propose a dynamic that can foster knowledge sharing and the active participation of students in the learning process. Thus, the present text aims to report the application of a gamified proposal, using the space of the classroom as a scenario to motivate and enhance the study of students, elementary education, involving them in the process of creating and resolving issues contextualized.
\end{abstract}

Resumo. As discussões em torno do potencial dos jogos transformaram o ensino e a aprendizagem e têm desafiado educadores a encontrarem soluções aplicáveis e que contribuam efetivamente com a aprendizagem dos estudantes. Integrar a gamificação e o uso de recursos tecnológicos em ambientes educacionais propõem uma dinâmica que pode propiciar compartilhamento de conhecimentos e participação ativa dos alunos no processo de aprendizagem. Desta forma, o presente artigo tem como objetivo relatar a aplicação de uma proposta gamificada, utilizando o espaço da sala de aula como cenário para motivar e potencializar o estudo dos alunos do ensino fundamental, os envolvendo no processo de criação e resolução de questões contextualizadas.

\section{Introdução}

Utilizar questionários para fixar um conteúdo é uma prática comum no Ensino Fundamental. Essa prática é pautada numa dinâmica simples: professores elaboram questões, alunos realizam a atividade e, finalizando o processo, essas questões são corrigidas. Nesse processo, os alunos respondem os questionários na perspectiva de que algumas dessas questões irão compor uma atividade avaliativa e os professores continuam no centro do conhecimento de atividades como esta, pois elaboram e corrigem as questões.

Nos dias atuais, os professores precisam compreender que os alunos constroem conhecimento, adquirem habilidades, desenvolvem hábitos mentais e disposições positivas em relação à aprendizagem [Rolando et al. 2015]. Tentando considerar que os alunos possuem as características citadas e inserindo a isso o advento da internet, os 
VII Congresso Brasileiro de Informática na Educação (CBIE 2018)

Anais do XXIV Workshop de Informática na Escola (WIE 2018)

questionários passaram a ser realizados no computador, substituindo o modelo tradicional do caderno e lápis.

Essa prática de responder os questionários precisa ser ressignificada. Tornar o processo interativo, colaborativo, no qual os alunos participam de forma ativa e professores sejam de fato mediadores do conhecimento é um desafio que pode se tornar real. A gamificação é um caminho alternativo que pode ser utilizado com o intuito de ressignificar a prática educativa. Vianna (2013) define gamificação como o uso de elementos de jogos e técnicas de game design em atividades diversas externas aos jogos. Portanto, o processo de responder questionários poderia ser transformado em uma atividade gamificada, na qual os alunos concebem suas questões e competem com seus pares. São utilizados diversos elementos de jogos, tais como enredo, pontuação, ranking, entre outros, com o objetivo engajá-los na execução da atividade proposta.

O presente trabalho apresenta uma prática educativa gamificada chamada War Questions, na qual os alunos elaboraram questões contextualizadas de diferentes níveis para o conteúdo de Matemática de equações do $2^{\circ}$ grau. A prática foi aplicada em quatro turmas do $9^{\circ}$ ano de uma escola privada de Natal, Rio Grande do Norte, tendo os professores como mediadores do conhecimento.

Além desta introdução, o artigo está estruturado da seguinte forma: a seção 2 traz a fundamentação teórica a respeito de uso de aspectos de jogos digitais em práticas educacionais e a sua influência no cotidiano; a seção 3 apresenta a metodologia e processos para o modelo War Questions; a seção 4 apresenta os resultados obtidos a partir da prática e discussões a esse respeito; a seção 5 apresenta as considerações a respeito do trabalho e a seção 6 segue com as referências utilizadas.

\section{Dos jogos digitais a gamificação}

Os jogos digitais tornaram-se poderosas ferramentas de entretenimento no mundo, para públicos de variadas idades. No contexto atual, essas ferramentas são bastante relevantes no cenário social na atualidade, no que diz respeito ao caráter técnicocientífico e principalmente econômico [Fleury, Nakano e Cordeiro 2014]. Diante disso, é possível notar que o envolvimento com os jogos digitais é tão grande e significativo quando percebermos a evolução digital, que os permeia desde sua criação rudimentar em laboratórios, perpassando por arcades, plataformas de jogos de uso público, até os consoles, popularmente conhecidos com videogames no Brasil.

Em se tratando do âmbito educacional, sabe-se que existem várias concepções de ensino, e cada uma delas reflete acerca das necessidades apontadas pela sociedade. As práticas pedagógicas, por sua vez, ainda estão muito dependentes e enraizadas nos direcionamentos do professor, resultado de suas vivências e concepções, que o fazem propagar a ideia de que a forma como ensina é única e correta, muitas vezes se tornando condição imposta para os aprendentes [Pelizzari et al. 2002].

Porém, com os avanços da sociedade e da tecnologia, surge a necessidade de serem ensinadas outras habilidades e competências, antes não adquiridas na escola, para que o indivíduo saiba, da melhor maneira, relacionar-se com o mundo a sua volta. Deve-se ensinar com metodologias diferentes, que envolvam os alunos já ambientados aos estímulos diários proporcionados pela tecnologia. 
VII Congresso Brasileiro de Informática na Educação (CBIE 2018)

Anais do XXIV Workshop de Informática na Escola (WIE 2018)

O psiquiatra norte-americano William Glasser propõe em seu livro Teoria da Escolha que, ao fazermos algo praticando (colocando a mão na massa), aprendemos cerca de $80 \%$ do que nos é ensinado. Isso significa $60 \%$ a mais do que se estivéssemos somente ouvindo alguém falando. Além disso, afirma que a motivação para estudar nasce de dentro para fora, ou seja, parte do próprio indivíduo [Glasser 2001]. Com isso, o aluno, quando colocado como protagonista de sua aprendizagem, pode ter melhores ganhos no processo de ensino e de aprendizagem. Glasser propõe também, no mesmo livro, uma pirâmide que mostra as formas de aprendizagem, dando ênfase aos aspectos destacados (ver Figura 1).

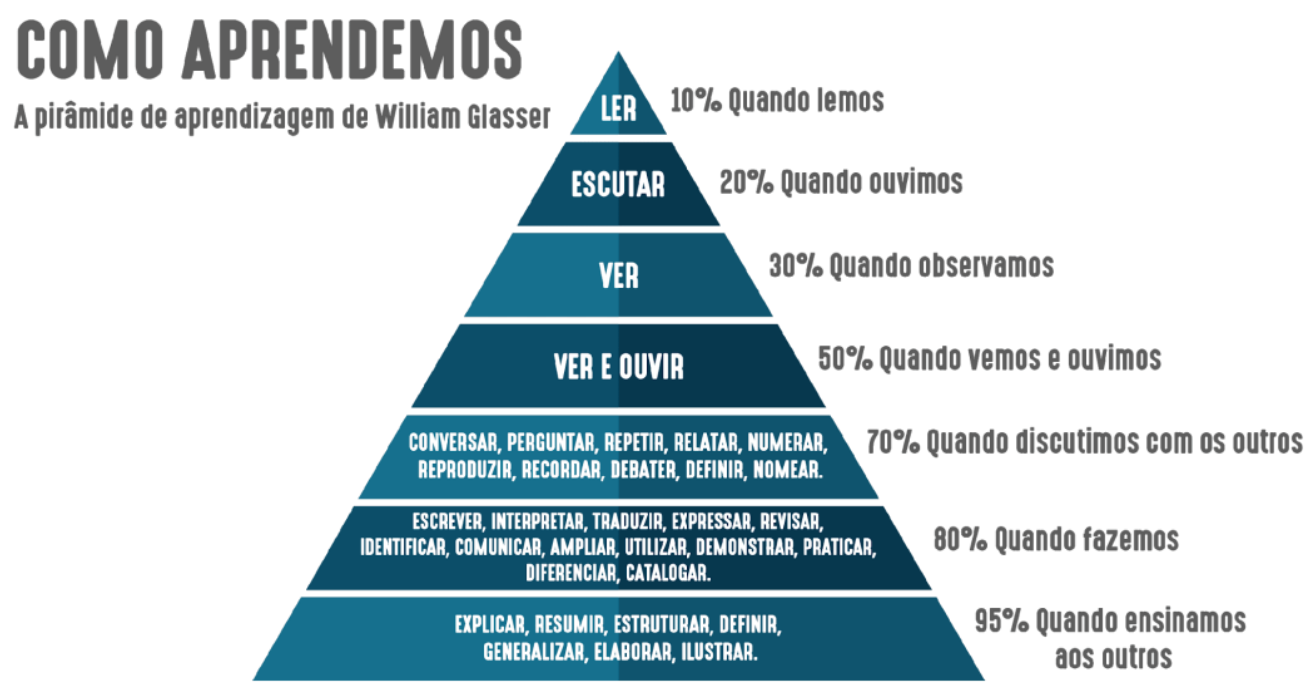

Figura 1. A Pirâmide de Aprendizagem de William Glasser (Foto: Sucesso em Vendas/Divulgação)

Compreendendo que o aprendizado significativo ocorre quando o aluno é posto como protagonista, muitos estudos comprovam que os jogos digitais são ferramentas em potencial para o desenvolvimento do processo de ensino e de aprendizagem. Nesse cenário, surgiu o termo gamificação, do inglês gamification, que de acordo com Werbach e Hunter (2012), está baseado na utilização de elementos peculiares dos jogos digitais em outros contextos externos aos jogos, quais sejam: mecânica, ou seja o funcionamento dos jogos; estratégias; raciocínio, com o intuito de motivar e envolver os indivíduos à prática de uma ação; resolução de um problema e promover o aprendizado de um conteúdo, habilidades ou competências através de uma prática gamificada.

Desse modo, de acordo com Figueiredo, Paz e Junqueira (2015), diversas abordagens e possibilidades pedagógicas emergem na contemporaneidade, dado o contexto social e tecnológico e os novos hábitos e práticas sociais. A gamificação vem adentrando a educação nos últimos anos, tendo em vista que os alunos do XXI são exímios jogadores, como apontam as pesquisas de Sheldon (2012), que demonstram resultados positivos do uso da gamificação na educação.

Diante desses apontamentos, deve-se considerar que os atuais alunos são inseridos nas linguagens e dinâmicas dos jogos desde de cedo, tendo em vista que o acesso à tecnologia digital só aumenta no mundo todo [Papert 2008]. Os jogos com seus elementos e estratégias são mecanismos motivacionais, pois estão presentes na vida das pessoas para que estas possam interagir com a máquina e com outras pessoas, além de proporcionar desafios, em que à medida que aprende, resolvem-se esses desafios [Figueiredo, Paz e Junqueira 2015]. Existe uma significação intrínseca que parte de 
VII Congresso Brasileiro de Informática na Educação (CBIE 2018)

Anais do XXIV Workshop de Informática na Escola (WIE 2018)

dentro para fora, pois a medida que resolve-se os desafios, há recompensa, fatores que envolvem o ego e a satisfação.

A motivação aditiva, que diz respeito a recompensas e sentimentos que agradam, é o modelo mais utilizado pelos jogos digitais [Chou 2015]. A motivação subtrativa, por sua vez, é um modelo no qual os indivíduos são motivados pelo medo, ansiedade, ou que algo ruim aconteça. A motivação também permeia, quando extrínseca, elementos universais de motivação como alimentação, dinheiro, etc.; e quando intrínseca, a motivação parte de dentro do indivíduo, ou seja, é particular como a auto-realização e a auto-estima. Podemos dizer então que a motivação perpassa por ações que são externas e que fazem o indivíduo querer obter ou ter medo de perder algo; ou partem de dentro do indivíduo, ações particulares de significado singular para cada indivíduo.

Quanto aos jogos digitais, estes são feitos para divertir e prender a atenção das pessoas, aos serem utilizados elementos para chamar a atenção dos usuários e principalmente para fazer com que eles permaneçam a jogar. Os principais desses elementos são: a pontuação, os personagens e a estória, porém, existem diversas táticas de gamificação, além dessas já citadas, que podem tornar uma prática de fato gamificada [Chou 2015].

Um das táticas mais importantes, levando em consideração a pesquisa mostrada anteriormente na pirâmide de Glasser (2001) de como as pessoas aprendem, é o meaning. Essa tática de gamificação trata de dar significado ao usuário, de o colocá-lo como protagonista da estória, da sua trajetória, é fazer o usuário sentir-se parte de algo e que tem uma missão a cumprir. Um exemplo, nos jogos digitais seria a criação do personagem, em que o indivíduo pode personalizá-lo no jogo conforme suas preferências e assim sentir-se como parte integrante do cenário, aumentando o seu significado e envolvimento.

Por fim, os estudos sobre gamificação na educação ainda são muito recentes [Figueiredo, Paz e Junqueira 2015]. Podemos observar, segundo os autores, que várias práticas/táticas dos jogos digitais são utilizadas na educação. Se agregado a isso, considerarmos a colaboração dos usuários (alunos aprendendo com seus pares), a tendência é que esse aprendizado obtenha cada vez mais significado.

\section{Metodologia War Questions}

Para atingir o objetivo do trabalho, nos inspiramos nas ideias de Sheldon (2012) para conceber uma solução gamificada para a sala de aula, chamada War Questions, adaptando o conteúdo e a linguagem utilizada durante toda a atividade. Esta solução foi aplicada para motivar e engajar os alunos na atividade de criação e resolução de questões contextualizadas em diferentes níveis de dificuldade.

Essa metodologia foi aplicada em uma disciplina de Matemática para alunos de 4 turmas do $9^{\circ}$ ano do Ensino Fundamental de um colégio particular da cidade de Natal/RN. Em cada uma dessas turmas, os alunos foram divididos em grupos para juntos executarem a atividade proposta. Ao todo, 110 alunos participaram dessa prática aplicando o conteúdo de Equações do $2^{\circ}$ grau no decorrer de 4 tempos de aulas.

A proposta foi elaborada seguindo os passos apresentados na Figura 2, quais sejam: (01) definição do conteúdo a ser gamificado; (02) escolha dos elementos do jogo 
VII Congresso Brasileiro de Informática na Educação (CBIE 2018)

Anais do XXIV Workshop de Informática na Escola (WIE 2018)

que integrem a proposta; (03) elaboração dos desafios que os alunos devem cumprir; (04) prototipação da dinâmica a ser aplicada; e (05) teste da proposta com um grupo de alunos [Sheldon 2012].

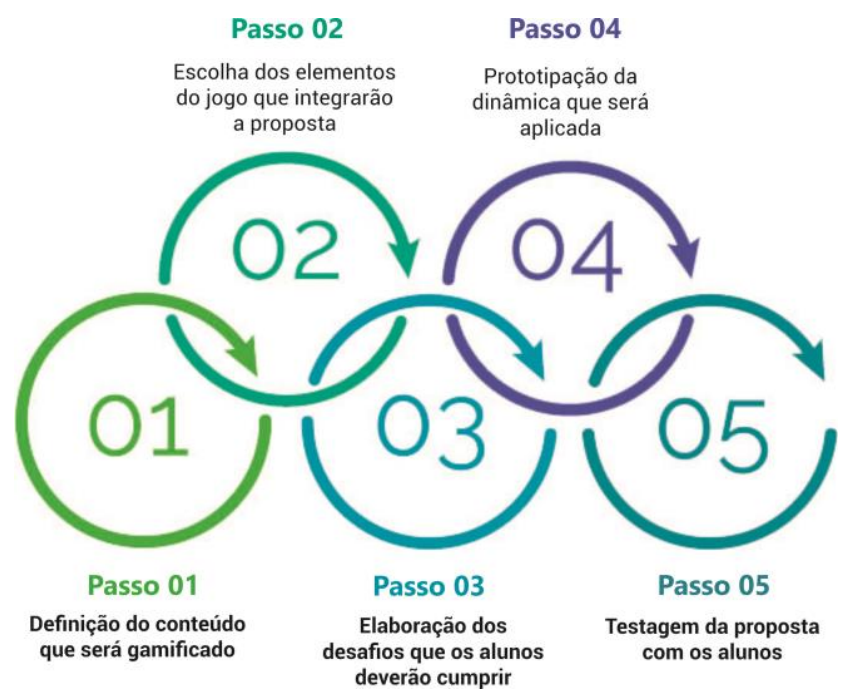

Figura 2. Passos para desenvolver a proposta - readaptado de Sheldon (2012).

Inicialmente, para a aplicação desta proposta precisávamos de um assunto cujo conteúdo já tivesse sido abordado anteriormente em sala de aula, pois para criar e responder questões o conhecimento prévio do assunto era primordial para esta atividade, por isso o assunto escolhido foi Equações do $2^{\circ}$ grau. No processo de elaboração da proposta, nosso segundo passo foi selecionar os elementos do jogo que se encaixavam com o nosso propósito. Como aspectos da gamificação, selecionamos avatares para representar cada grupo e medalhas para indicar o êxito ou não na realização da atividade.
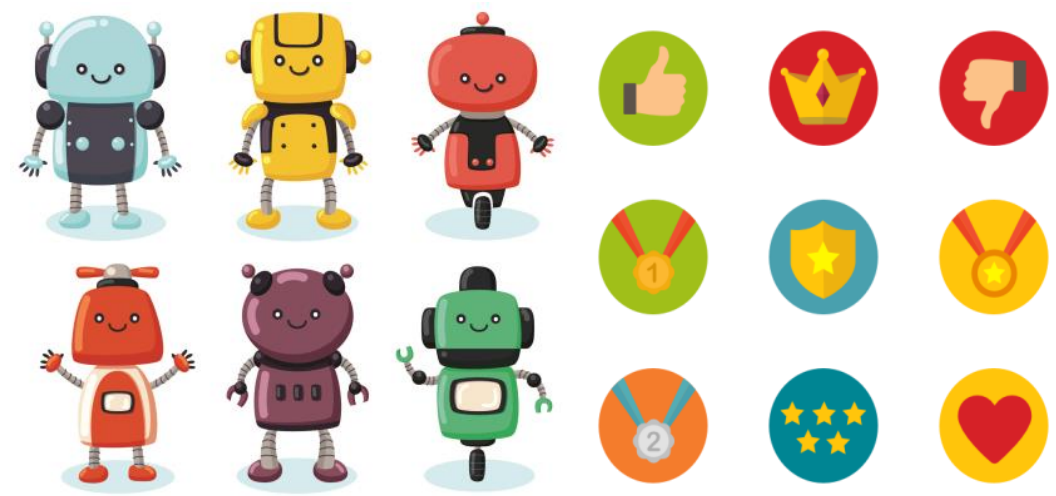

Figura 3. Avatares e medalhas (Fonte: http://www.freepik.com)

Decidimos não nominar os personagens e/ou as medalhas para deixar a escolha do significado a cargo dos próprios alunos, segundo o ícone que o ilustra (ver Figura 3). Em seguida, elaboramos os desafios que os alunos iriam cumprir durante a atividade. Estes desafios estavam dispostos em uma tabela (ver Figura 4) que foi entregue aos alunos no início da aula. 
VII Congresso Brasileiro de Informática na Educação (CBIE 2018)

Anais do XXIV Workshop de Informática na Escola (WIE 2018)

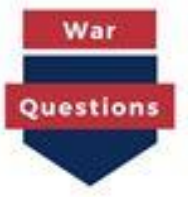

Nome Grupo:

Líder grupo:

Tabela de Desafios War Questions

\begin{tabular}{|l|l|l|}
\hline Tarefas & Pontuação & Medalhas (nome) \\
\hline $\begin{array}{l}\text { 1 - Criar as três questões no prazo } \\
\text { estipulado pelos professores }\end{array}$ & & \\
\hline 2a - Responder a lista geral de questões & & \\
\hline $\begin{array}{l}\text { 2b-Classificar questões - fáceis, } \\
\text { dificeis, chatas e legais }\end{array}$ & & \\
\hline $\begin{array}{l}\text { 3 - Modificar as questões eleitas como } \\
\text { mais chatas e torná-las legais. }\end{array}$ & & \\
\hline $\begin{array}{l}\text { 4 - Responder a pesquisa final } \\
\text { sls. quisalegrelato }\end{array}$ & & \\
\hline $\begin{array}{l}\text { 4a - Ter as questões do seu grupo } \\
\text { escolhidas como as mais legais }\end{array}$ & & \\
\hline 4b - Participação no grupo & & \\
\hline 4c -Comportamento da turma & & \\
\hline Pontuação final & $100 \%$ & \\
\hline
\end{tabular}

Espaço para as questões modificadas.

Figura 4. tabela entregue aos grupos de alunos.

Cada grupo recebeu uma tabela impressa em uma folha de tamanho A4, no início da prática. Nela, os alunos identificaram o grupo e o avatar escolhido. A Figura 4 ilustra a estrutura da tabela, com suas quatro fases e as tarefas que cada grupo deveria cumprir para avançar dentro do jogo. De acordo com o conteúdo proposto, os grupos tinham como missão inicial a criação de três questões, em diferentes níveis de dificuldade: fácil, médio e difícil, em um formulário compartilhado pelo professor e 
VII Congresso Brasileiro de Informática na Educação (CBIE 2018)

Anais do XXIV Workshop de Informática na Escola (WIE 2018)

dentro do prazo estipulado. Os alunos tiveram acesso ao Google Formulários para o cumprimento dessa primeira parte.

Feito isso, a fase 2 exigiu que os alunos respondessem as questões elaboradas pelas outras equipes. Para isso, o professor disponibilizou o link contendo todas as questões criadas na turma. Neste momento, cada equipe, ao responder as questões, classificou-as em fáceis, difíceis, chatas e legais de acordo com a opinião dos componentes do grupo. $\mathrm{Na}$ fase 3, a missão do grupo era modificar as questões eleitas como chatas e torná-las legais. Essa mudança da questão deveria ser feita na própria folha impressa do desafio. Na quarta e última fase, os alunos precisavam responder uma pesquisa final, disponibilizada em um outro link e quantificar em porcentagem quanto valia ter as questões do seu grupo escolhidas como as mais legais, a participação do grupo na realização da atividade e o comportamento da turma.

Ainda em grupo, os aluno precisavam nomear as medalhas referentes a cada uma das fases, bem como, quantificar em porcentagem quanto valia o cumprimento de cada item do desafio. Em todo desafio, cada vez que o grupo mudava de fase, um de seus componentes precisava avançar com o Avatar do grupo no quadro em que todas as fases e avatares estavam dispostos.

A prototipação da dinâmica foi executada pelo professor, para que os elementos desta metodologia fossem disponibilizados para os alunos no decorrer da atividade. Desta forma, a escolha dos Avatares e das medalhas, a elaboração da tabela e dos formulários, bem como a impressão de todos esses elementos foi feita antecipadamente.

De posse de todo material prototipado, a última fase foi a testagem desta proposta com os alunos. A aplicação e validação do War Questions será detalhada na seção a seguir.

\section{Resultados e Discussões}

Inicialmente, as equipes elaboraram suas questões, inserindo-as em um arquivo compartilhado pelos professores no Google Formulários. Após esta elaboração, cada equipe escolheu um avatar (robô), dentre os apresentados na Figura 4, para representar seu grupo na atividade. O avatar escolhido por cada equipe foi fixado no quadro enquanto toda a equipe recebia um botom com a mesma imagem deste personagem. Em seguida, uma tabela, contendo os desafios que o grupo precisava cumprir no decorrer da atividade, foi distribuída para cada grupo registrar seu próprio avanço.

Os formulários contendo as questões de todos os grupos foram compartilhados com toda a turma. Os alunos utilizaram celulares, tablets e também notebooks para acessar e responder ao formulário online. Alguns preferiram resolver as questões em duplas, outros individualmente, mas sempre comparando e compartilhando os resultados entre si. Os alunos que estavam tendo mais dificuldades contaram com a ajuda do professor para entender o caminho da resolução da questão.

Neste percurso, eles mesmos perceberam que algumas questões haviam sido elaboradas erroneamente. Neste caso, o professor era acionado no grupo para ajudá-los a reformular a questão ou encontrar o motivo de invalidez do item. Trabalhar em cima do erro também foi motivo para aprendizagem neste momento. 
VII Congresso Brasileiro de Informática na Educação (CBIE 2018)

Anais do XXIV Workshop de Informática na Escola (WIE 2018)

Além de cumprir as tarefas, os alunos precisaram discutir em grupo sobre a importância de cada atividade e quantificar (em porcentagem) o valor de cada uma delas. As somas desses valores deveriam corresponder a 100\%. Desta forma, os alunos participaram diretamente da formatação da avaliação e entenderam que, nesta proposta, o processo é mais importante que o resultado.

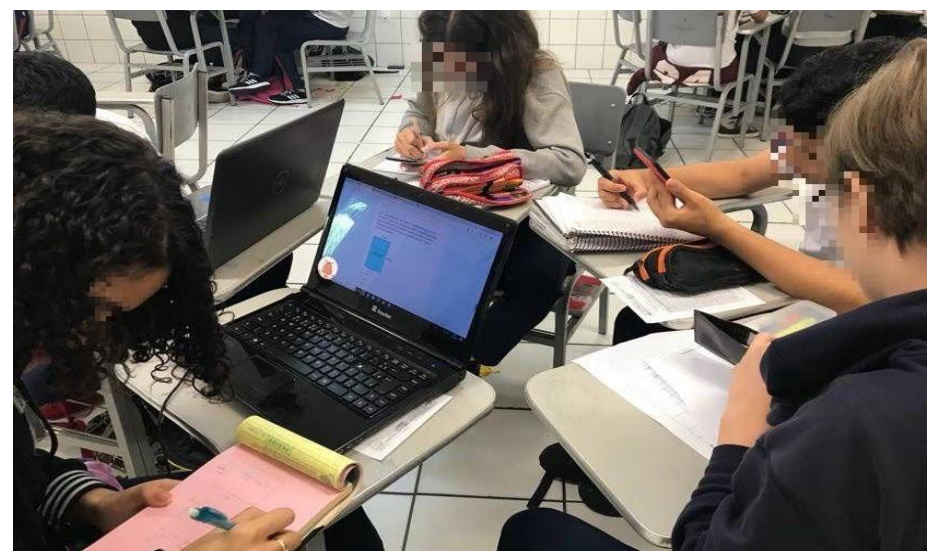

Figura 5. Alunos resolvendo as questões do questionário

Uma vez finalizada a atividade de elaboração das questões, foi dado início à etapa de resolução das questões de todos os grupos (ver Figura 5). Os professores circularam pelos grupos durante toda a atividade, tirando dúvidas e observando como se dava a interação entre os alunos, tanto na resolução das questões quanto na execução das demais atividades. Percebemos, durante a atividade, que quase todos os alunos demonstram empenho, restando apenas um ou outro ainda sem interesse em colaborar com o grupo. Em diversos momentos os professores perceberam que os alunos estiveram envolvidos com a atividade gamificada e encararam a proposta como um desafio, cumprindo todas as etapas.

A cada mudança de fase um integrante do grupo deslocou seu personagem na linha do tempo e os demais alunos da turma acompanharam atentamente, especialmente os dos outros grupos.

A avaliação se deu durante todo o processo. O professor observou o comportamento dos alunos desde a elaboração das questões até sua resolução. Os alunos responderam os questionários e obtiveram uma nota pela quantidade de acertos das questões resolvidas. $\mathrm{O}$ valor em porcentagem atribuído para cada uma dos desafios pelos alunos também foi levado em consideração, mas os números apresentados por todos os grupos não tiveram tanta variação de um para o outro. No final, em pouco tempo, os alunos demonstraram muita produtividade e compromisso com todo $\mathrm{o}$ processo.

\section{Considerações Finais}

Na educação, criar uma experiência de gamificação rica e envolvente não é uma tarefa simples. É preciso analisar o público alvo, o ambiente, o objeto de aprendizagem que se quer atingir e o tempo para experimentar o jogo. Após isso, aplicar os elementos e os recursos da mecânica dos jogos que serão utilizados para personalizar e caracterizar a 
VII Congresso Brasileiro de Informática na Educação (CBIE 2018)

Anais do XXIV Workshop de Informática na Escola (WIE 2018)

atividade como um jogo. Por fim, testar e ajustar a atividade de acordo com o feedback que cada experiência alcançou.

No presente trabalho, a indicação de sucesso que a metodologia War Questions pôde atingir foi mensurada pelo relato de professores e alunos que responderam positivamente à proposta e relataram que desejam praticá-la outras vezes. $\mathrm{Na}$ perspectiva dos alunos, é importante ressaltar o trabalho cooperativo para elaboração das questões e a competição para atingir o máximo de pontos, fato que colaborou com a sistematização do conteúdo exercitado. Os professores viabilizaram uma proposta gamificada, transformando uma atividade enfadonha em um jogo motivador para a aquisição do conhecimento e ainda demonstraram flexibilidade para contornar os problemas que surgiram como a elaboração de questões erradas por parte dos alunos, além do curto tempo para realizar toda a atividade.

A gamificação aplicada à educação pôde, através dos elementos do jogo, engajar alunos em atividades tidas anteriormente como chatas e monótonas. Como trabalhos futuros, pretendemos transformar essa proposta e criarmos uma plataforma gamificada online de aprendizagem multiplayer, fazendo as devidas adaptações para o ambiente virtual. Desejamos, ainda, testar a solução para diferentes contextos e conteúdos, propondo um tempo maior para aplicação, além de novas adaptações de acordo com o feedback de cada aplicação.

\section{Referências}

Chou, Y.-k. (2014) "Octalysis complete gamification framework", http://yukaichou.com/gamification-examples/octalysis-complete-gamificationframework/, junho.

Chou, Y.-k. (2015). “Actionable Gamification: Beyond Points, Badges, and Leaderboards". Leanpub.

Glasser, W. (2001). Teoria da escolha: uma nova psicologia de liberdade pessoal. São Paulo: Ed. Mercuryo.

Fleury, A.; Nakano, D.; Cordeiro, J.H.D.O. (2014) Mapeamento da indústria brasileira e global de jogos digitais. São Paulo: GEDIGames/USP.

Figueiredo, M. ; Paz, T. ; Junqueira, E.; (2015) "Gamificação e educação: um estado da arte das pesquisas realizadas no Brasil”. Publicado nos Anais dos Workshops do IV Congresso Brasileiro de Informática na Educação (CBIE 2015). p.1154-1163.

Papert, S. (2008). A Máquina das Crianças: repensando a escola na era da informática. Artmed, Porto Alegre.

Pelizzari, A. et al (2002) Teoria da Aprendizagem Significativa segundo Ausubel. In: Rev. PEC, Curitiba, v.2, n.1, p.37-42.

Rolando, L. G. R.; Luz, M. R. M, P. D.; Salvador, D. F. (2015) “O conhecimento tecnológico pedagógico do conteúdo no contexto lusófono: uma revisão sistemática da literatura". Revista Brasileira de Informática na Educação (RBIE), v.23(3), p.174190. 
VII Congresso Brasileiro de Informática na Educação (CBIE 2018)

Anais do XXIV Workshop de Informática na Escola (WIE 2018)

Sheldon, L. (2012) "The Multiplayer Classroom: Designing Coursework as a Game". Boston, MA: Cengage Learning.

Vianna, Y. et al. (2013) “Gamification”, Inc. São Paulo: MJV Press.

Werbach, K.; Hunter, D. (2012) "For The Win: How Game Thinking Can Revolutionize Your Business". Filadélfia, Pensilvânia: Wharton Digital Press. 